\title{
India's Contribution to Mitigating the Impacts of Climate Change through Vegetation
}

\section{Management}

\section{J. Dash'; M. D. Behera²; C. Jeganathan ${ }^{3}$; C. S. Jha ${ }^{4}$; S. Sharma'; R. Lucas ${ }^{6}$; A. A. Khuroo7; A. Harris ${ }^{8}$; P. M. Atkinson ${ }^{1}$; D. S. Boyd ${ }^{9}$; C. P. Singh ${ }^{10}$; M. P. Kale ${ }^{11}$; P. Kumar ${ }^{12}$; Soumit. K. Behera ${ }^{13}$; V.S. Chitale ${ }^{2}$; S. Jayakumar ${ }^{14}$; L. K. Sharma ${ }^{3 \$}$;} A. C. Pandey ${ }^{3}$; K. Avishek ${ }^{3}$; P.C. Pandey ${ }^{15}$; S.N. Mohapatra ${ }^{16}$; S. K. Varshney ${ }^{17}$

Across India, human-driven land use and climate changes are altering the structure, functioning and extent of ecosystems $(1,2)$ and, in-turn, these affecting regional bio-geochemical feedbacks. This is evident from the fact that, there is an increase in the length of vegetation growing season (3); in the Himalayas, vegetation is advancing to higher elevations and the overall productivity is increasing where conditions (e.g., soils, aspect) allow $(4,5)$.

Therefore, these changes in natural ecosystems also provide a potential opportunity to increase carbon sink capacity and thereby contribute to mitigating climate change impacts. Human-directed initiatives such as the National Mission for a Green India (6) launched by the Government of India is focusing on increasing forest density by decentralising forest management and interventions at a local scale; the mission has a target to increase carbon sequestration by 60 million tonnes by 2020 . There are also many areas that might potentially support vegetation into the future, particularly where elements of the original ecosystem remain (7). In each case, a substantial, but as yet un-quantified amount of carbon can be sequestered annually (8). In particular, the Indian tropics and the large ecological variation within the country provide the advantage of diverse niches and offer opportunities to elucidate comparative adaptation biology, including the role of biotic factors, at different levels of organization from populations to ecosystems. For this reason, it is recommended that India puts in place a programme that allows actual and potential carbon sequestration to be quantified and monitored on a regular basis.

India has a strong network of scientific institutions located in various bio-geographical provinces and a dedicated Space Programme through the Indian Space Research Organisation (ISRO), which currently operates one of the largest constellations of satellites. The last four decades of research and development in the Indian space science community has been primarily application driven in response to the initial vision of the government space programme, which was focused on the use of space technology for national development. A large proportion of the collected data, particularly those obtained from Earth observation satellite sensors, are used for direct societal benefits such as natural resources and disaster management and mapping. In contrast, space programmes developed in the west, such as those operated by the European Space Agency (ESA) and the National Aeronautics and Space Administration (NASA), are largely science-driven and data from these missions are regularly used to investigate scientific questions of regional-to-global importance. As a consequence, the full potential of the Indian space programme is yet to be realized by the scientific community.

\footnotetext{
${ }^{1}$ Geography and Environment, University of Southampton, UK

${ }^{2}$ Centre for Oceans, Rivers, Atmosphere and Land Sciences (CORAL), Indian Institute of Technology (IIT) Khargpur, W.B., India ${ }^{3}$ Department of Remote Sensing, BIT, Mesra, India ( ${ }^{\$}$ Currently at Centre for Land Resource Management, Central University of Jharkhand, Brambe, Ranchi, India)

${ }^{4}$ Forestry and Ecology Group, National Remote Sensing Centre (ISRO), Hyderabad, A.P., India

${ }^{5}$ G.B. Pant Institute of Himalayan Environment Development (MOEF), Kosi-Almora; Uttarakhand, India

${ }^{6}$ Institute of Geography and Earth Sciences, Aberystwyth University, UK

${ }^{7}$ Centre for Biodiversity and Taxonomy (CBT), Department of Botany, University of Kashmir, Srinagar, J \& K, India

${ }^{8}$ School of Environment and Development, University of Manchester, UK

${ }^{9}$ School of Geography, University of Nottingham, UK

${ }^{10}$ Space Applications Centre (ISRO),Satellite Road, Jodhpur Tekra, AmbawadiVistar P.O., Ahmedabad, India

${ }^{11}$ Centre for Development of Advanced Computing (C-DAC); Pune, Maharastra, India

${ }^{12}$ Sikkim State Forest Department (MOEF), Gangtok, Sikkim, India

${ }^{13}$ Plant Ecology and Environmental Sciences Division, National Botanical Research Institute (CSIR), Lucknow, India

${ }^{14}$ Department of Plant Ecology and Environmental Sciences, School of Life Sciences Pondicherry University, Pondicherry, India

${ }^{15}$ School of Earth, Ocean \& Climate Sciences; Indian Institute of Technology Bhubaneswar, India

${ }^{16}$ School of Studies in Earth Science, Jiwaji University, Gwalior, India

${ }^{17}$ Department of Science and Technology, Technology Bhawan, New Mehrauli Bhawan, New Delhi, India
} 


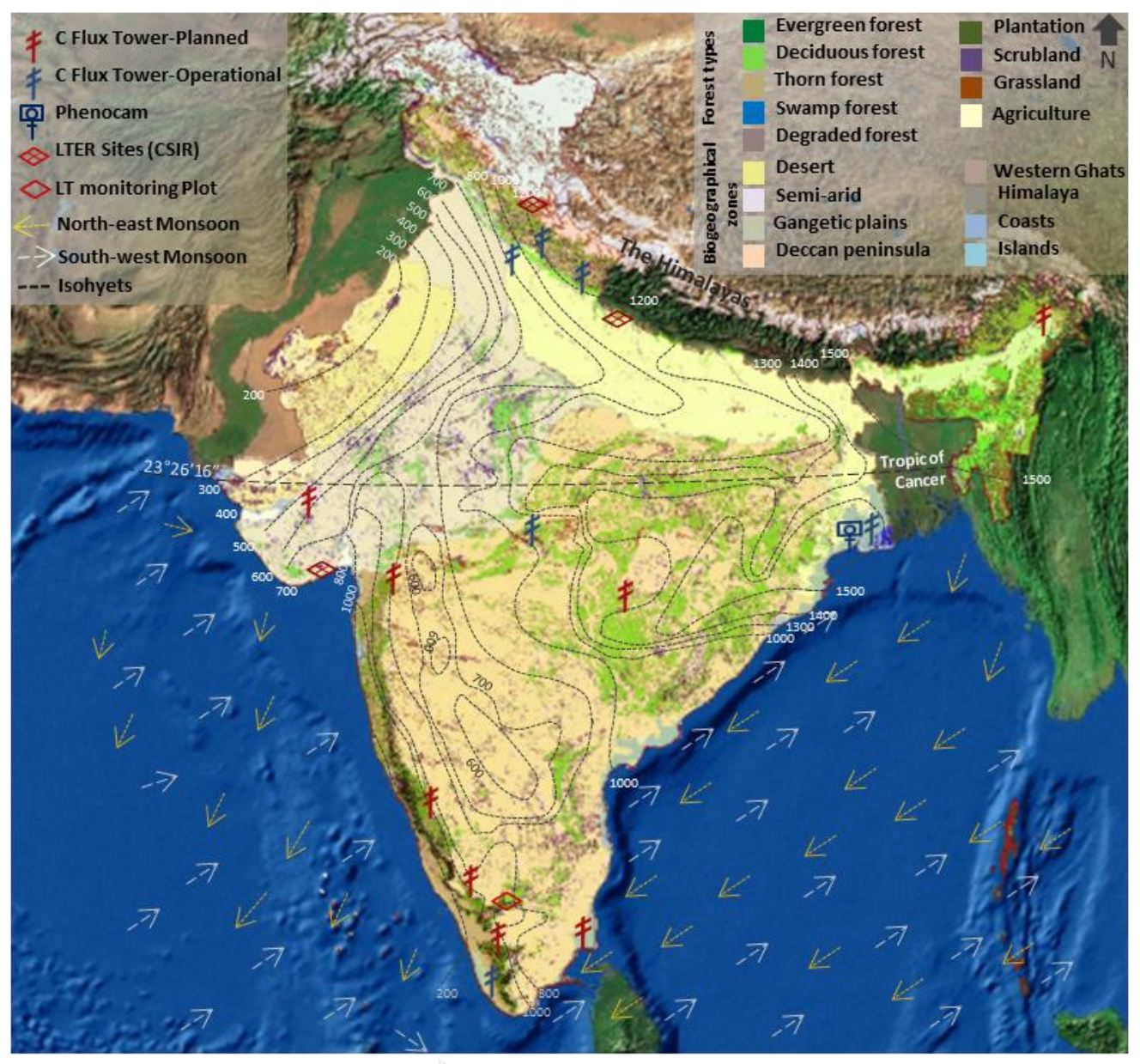

Figure 1: Climatic, topographic and natural vegetation diversity across India. Isohyets are shown in dotted lines. South-west and north-east India with high annual precipitation $(1000-1500 \mathrm{~mm})$ provide favourable conditions for evergreen and moist deciduous forests, whereas western and north western regions with low annual precipitation accommodate desertic and semi-arid ecosystems. The Himalayan orography has a profound effect on the precipitation pattern. White coloured arrows indicate the path of the south-west monsoon (Summer), while yellow coloured arrows indicate the path of the north-east monsoon (Winter). The figure also shows the location of operational and planned flux towers, Long-Term Ecological Record (LTER) sites, long-term monitoring plots and Phenocam. It clearly shows the need for further ground networks in the under-represented central, western and north-east regions to understand ecosystem carbon dynamics.

Over the last decade, India has tripled its expenditure in Research and Development funding, but at less than $1 \%$ of the GDP its still fall short of major nations. However, with an aim to double its current expenditure in R\&D over next five year to $2 \%$ of GDP, suggest that scientific research is higher on the country's agenda (9). The current Indian Prime Minister Sri Narendra Modi portrays India as a responsible country in terms of climate action. In 2018, he told to World leaders that climate change is the greatest threat to the survival and human civilisation as we know it. India further outlines plans to increase tree cover to create an additional cumulative carbon sink of 2,500-3,000 Mt CO2e by 2030-roughly on a par with its total emissions across one year. This ambitious science policy initiative led by the top political leadership will surely provide a stimulus to scientific research, particularly by leveraging the capabilities in universities and research institutes across the country. One of the priority areas for both policy-makers and 
scientists, based upon Indian strength in the development of space science, should be to utilise the data from satellite sensors to understand Earth system processes and the impacts of climate change. However, with rich biodiversity and complex vegetation-soil-atmosphere interactions across the country, the programme needs a set of priorities to provide a clear-cut mechanism for increasing scientific understanding of Earth system processes based on more science-oriented use of space data.

The Indo-UK Terrestrial Carbon Group (IUTCG) comprising both Indian and UK scientists, funded jointly by the Department of Science and Technology (DST), India and the Department of Business, Innovation and Skills (BIS) organised a workshop to explore ways in which Earth observation data can be effectively utilised in vegetation carbon modelling and how field measurements can be incorporated to improve estimation of the regional carbon budget (10). The IUTCG recommended establishment of the following:

(a) Continuous and long-term measurement of gas and energy fluxes, structural and functional properties of vegetation and subsequent extension to unrepresented ecosystems across India by integrating existing initiatives and developing low-cost tools of measurement.

b) An Indian Phenological Network (IPN) facilitating the long-term collection and collation of existing and new phenological observations through remote sensing, ground-based, and citizen science initiatives at local scale, and further up-scaling to the national level.

c) A Dynamic Vegetation Model (DVM) driven by satellite sensor and ground observations for India, feeding into a global model, and its subsequent integration with a land surface-atmospheric-ocean model; and thus allowing actual and potential carbon sequestration to be mapped under future land use and climate change scenarios. Existing DVMs are not able to simulate vegetation dynamics in India because of poor characterisation of India's varied forest types and rain-driven phenology.

d) A globally standardized system for quantifying carbon stocks and dynamics as well as energy fluxes through integration of remote sensing and field observations for India.

e) Capacity building to routinely scale up observations of vegetation, including carbon and energy fluxes, from local to national levels.

f) An institutional framework for the scientific community, policy makers and stakeholders for compiling, archiving, retrieving and seamless distribution of satellite and ground data through an Indian Ecological Observatory Network (IEON).

g) A science-policy mechanism that allows the use of time-series comparison of satellite sensor data to identify the areas of land with degraded or lost ecosystems that can potentially be restored through active vegetation management.

India already has a proven strength in many of the above highlighted areas of research, but specific scientific programmes, targeted policy initiatives and priority investment is required to operationalize the mechanisms outlined above. In particular, India has (i) extensive archives of satellite data available, which can be augmented with data available through other international space organisations (e.g., ESA, NASA and JAXA); (ii) ISRO's flux towers (6 operational; 8 planned) and India's Council of Scientific and Industrial Research's Long-term Ecological Record sites (2 operational) which provide the baseline data to characterise ecosystem processes at community level and, in turn, to quantify carbon exchange are important initiatives and (iii) a large number of field observation sites across the country collecting plot level and short to long-term changes in carbon density in vegetation phenology (figure 1). In the near future, bringing other unrepresented ecosystems across India under these initiatives and their cross-linkages with international observation networks (FLUXNET) should be the priority. 
The emphasis is rightly placed on the sequestration of vegetation carbon given the urgency to reduce the impacts of increasing levels of greenhouse gases in the atmosphere. However, there should also be an emphasis on providing remote sensing and other observations of carbon from Indian ecosystems, particularly forests and wetlands such as the Sundarbans. Effective integration of field observations, collected through various monitoring networks, and satellite sensor data is required to provide country-wide monitoring and increase understanding of the global carbon cycle. To achieve the above goal combined research effort, which spans many scientific fields including field biology, ecology and space science, is necessary. Given, India's growing position in the world, and the importance of climate science and initiatives to reduce in carbon emissions (REDD+) the above framework can provide crucial scientific understanding that can feed directly into climate change adaptation and mitigation policy. Therefore, a detailed science plan, a national governing body and a dedicated funding mechanism are essential to enable timely execution of these tasks.

\section{List for References:}

1. Ravindranath, N. H., \& Sukumar, R. (1998). Climate change and tropical forests in India. Climatic change, 39(2), 563-581.

2. Menon, S., Hansen, J., Nazarenko, L., \& Luo, Y. (2002). Climate effects of black carbon aerosols in China and India. Science, 297(5590), 2250-2253.

3. Menzel, A., \& Fabian, P. (1999). Growing season extended in Europe. Nature, 397(6721), 659-659.

4. Khuroo, A. A., Weber, E., Malik, A. H., Reshi, Z. A., \& Dar, G. H. (2011). Altitudinal distribution patterns of the native and alien woody flora in Kashmir Himalaya, India. Environmental research, 111(7), 967-977.

5. Sharma, S., \& Roy, P. S. (2007). Forest fragmentation in the Himalaya: A Central Himalayan case study. The International Journal of Sustainable Development \& World Ecology, 14(2), 201-210.

6. The National Mission for a Green India: Ministry of Environment and Forests. (2010). moef.nic.in/downloads/public-information/GIM-Report-PMCCC.pdf

7. Chazdon, R. L. (2008). Beyond deforestation: restoring forests and ecosystem services on degraded lands. Science, 320(5882), 1458-1460.

8. Lal, R. (2002). Soil carbon sequestration in China through agricultural intensification, and restoration of degraded and desertified ecosystems. Land Degradation \& Development, 13(6), 469-478.

9. Bagla, P. India Unveils Ambitious Science Policy: http://news.sciencemag.org/scienceinsider/2013/01/indiaunveils-ambitious-science-.html\#disqus_thread

10. Behera, M. D. \& Dash J. (2013). Terrestrial carbon studies and earth observation data. Current Science, 104(4), 413.

11. http://psa.gov.in/sites/default/files/pdf/RD-book-for-WEB.pdf [ replace this with 9 do proper formatting] 